A C G

Bioorg. Med. Chem. Rep. 3:2 (2020) 22-31

Bioorganic \&

Medicinal

Chemistry

Reports

\title{
Synthesis and biological evaluation of 1,3,5-triazine-substituted
}

ureido benzenesulfonamides as antioxidant, acetylcholinesterase

\author{
and butyrylcholinesterase inhibitors
}

\author{
Nebih Lolak ${ }^{1}$, Muhammed Tuneğ $\omega^{2}$, \\ Aslınur Doğan ${ }^{1}$, Mehmet Boğa ${ }^{(2 *}$ and Suleyman Akocak ${ }^{(1 *}$ \\ ${ }^{1}$ Adiyaman University, Faculty of Pharmacy, Department of Pharmaceutical Chemistry, 02040, \\ Adlyaman, Türkiye \\ ${ }^{2}$ Dicle University, Faculty of Pharmacy, Department of Analytical Chemistry, 21280, Diyarbakur, \\ Türkiye
}

(Received July 09, 2020; Revised August 23, 2020; Accepted August 24, 2020)

\begin{abstract}
A series of twenty 1,3,5-triazine-substituted ureido benzenesulfonamides 2 (a-e) and 3 (a-o) were resynthesized and assayed for antioxidant properties by using several different methods including 1,1-diphenyl-2picryl hydrazyl (DPPH) free radical scavenging assay, 2,2'-azino-bis-(3-ethylbenzothiazoline-6-sulfonic acid) (ABTS) cation radical decolarization assay, metal chelating and cupric reducing antioxidant capacity (CUPRAC) methods. The inhibitory effects of compounds on acetylcholinesterase (AChE) and butyrylcholinesterase (BChE) enzymes have been also demonstrated. All compounds showed a greater antioxidant capacity against ABTS assay by having a more potent activity than the standards BHT, BHA and $\alpha$-TOC. In general, all compounds were non susceptible to against $\mathrm{AChE}$ enzyme. On the other hand, several lead compounds were obtained from the current series against BChE enzyme. More specifically, compound $\mathbf{3 m}$ showed great inhibition profile against BChE with $\%$ inhibition value of 93.77 , which is better than the standard drug galantamine (\% inhibition value of 87.86).
\end{abstract}

Keywords: 1,3,5-triazine; sulfonamide; acetylcholinesterase; butyrylcholinesterase; antioxidant. (C2020 ACG Publications. All rights reserved.

\section{Introduction}

Sulfonamides are one of the most important pharmacophores that are used in a wide range of pharmaceutical applications such as 1,3,5-triazine; sulfonamide, antibacterial, anticancer, anti-inflammatory and antioxidant effective compounds. ${ }^{1-5}$ Furthermore, they are also used as a research tool for treatment of Alzheimers' disease with their effect on carbonic anhydrase enzyme inhibition. ${ }^{6,7}$ On the other hand, the 1,3,5-triazine group is known as the s-triazine scaffold finds an area of investigation with its antimicrobial, antiviral, diuretic, anticancer and anti-inflammatory effects. ${ }^{8-11}$ More specifically, recent studies have found that sulfonamides containing 1,3,5-triazine scaffolds have a selective and potent carbonic anhydrase (CA) inhibitory effect. ${ }^{12-15}$ In a recent study, it was determined by us that sulfonamides incorporating 1,3,5-triazine moieties act as potent $\mathrm{AChE}$ and $\mathrm{BChE}$ inhibitors. ${ }^{16}$

\footnotetext{
*Corresponding Authors: E-mails: mehmetboga1980@gmail.com (M.Boga); akocaksuleyman@gmail.com
} (S.Akocak) 
Alzheimer is a neurodegenerative disease characterized by cognitive impairments. ${ }^{17}$ It is estimated that almost 50 million people suffer from this disease, according to current reports. This number is thought to increase gradually. The disease is caused by the accumulation of beta-amyloid. Factors such as oxidative stress, inflammation, tau-protein aggregation, dishomeostasis of bio-metals, acetylcholine $(\mathrm{ACh})$ and butyrylcholine $(\mathrm{BCh})$ deficiencies are included in the pathophysiology of the disease. ${ }^{18-20}$

The enzyme AChE is present in high concentrations in the central and peripheral nervous system, parasympathetic synapses, and neuromuscular junctions. ${ }^{21}$ This enzyme is of great importance for the hydrolysis of ACh. In the physiological system, the presence of AChE level outside optimal values causes various diseases. Alzheimer and Parkinson disease are the main neurological diseases that occur with this condition. ${ }^{22}$ The enzyme BChE, also known as nonspecific cholinesterase, take a key part in the regulation of $\mathrm{BCh}$. $\mathrm{BChE}$ is an enzyme found in the blood, glia cells, central nervous system, liver, pancreas and heart. The $\mathrm{BChE}$ and $\mathrm{AChE}$ sequences are similar. Therefore, their success in treatment is similar. ${ }^{23,24}$ Various cholinesterase inhibitors such as tacrine, galantamine, donepezil and rivastigmin are used in the symptomatic treatment of Alzheimer disease. ${ }^{25}$ These drugs used in treatment have gastrointestinal side effects such as nausea, vomiting, diarrhea, novelization, syncope and weight loss. ${ }^{20-26}$ It is also thought that antioxidants exhibit protective effects against Alzheimer disease. ${ }^{27}$ For the treatment of Alzheimer disease, cholinesterase inhibitors with antioxidant effects and less toxic effects are needed. Therefore, the development of new cholinesterase inhibitors that are effective for the treatment of the disease and have a low side effect profile is of interest.

In our previous study, we synthesized new molecules by combining the 1,3,5-triazine scaffold and ureido benzenesulfonamide groups as a potent and selective carbonic anhydrase inhibitors. ${ }^{28}$ Hence, in the present study, our aim is to further investigation of the antioxidant and anticholinesterase enzyme activity of the 1,3,5-triazine-substituted ureido benzenesulfonamides $\mathbf{2}$ (a-e) and $\mathbf{3}$ (a-o).

\section{Experimental}

\subsection{Chemistry}

In our previous work, we have successfully synthesized and characterized the target compounds 2 (a-e) and $\mathbf{3}$ (a-o) as a potent and selective carbonic anhydrase inhibitors (Scheme 1). ${ }^{28}$

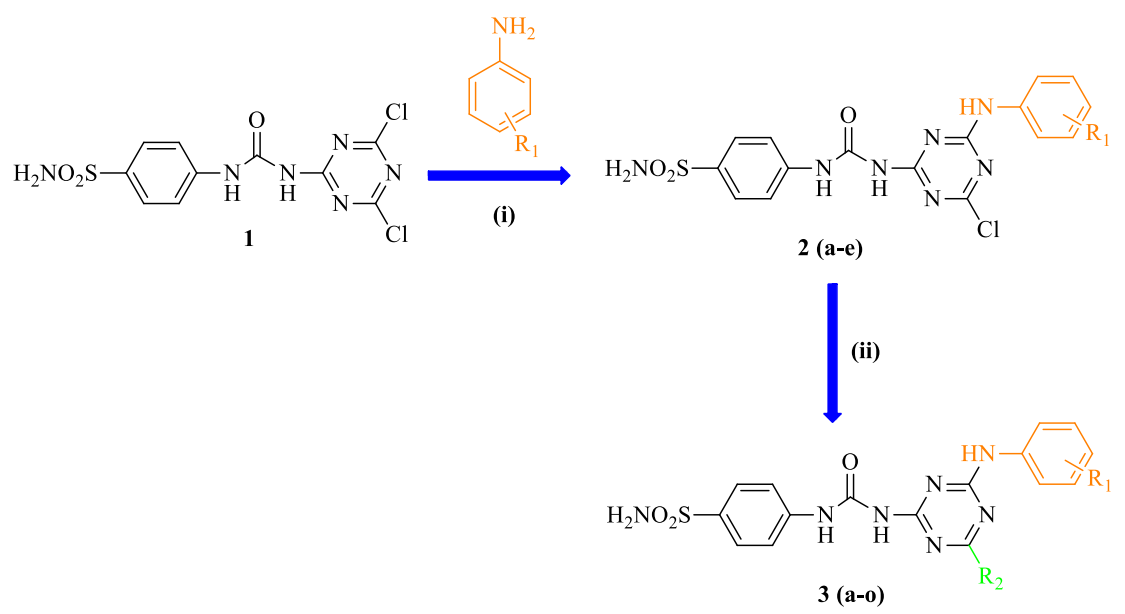

Scheme 1. General synthetic route for the synthesis of 1,3,5-triazine-substituted ureido benzenesulfonamides 2 (a-e) and 3 (a-o). Reagents and conditions: (i) $\mathrm{R}_{1} \mathrm{ArNH}_{2}, \mathrm{DMF}, 0$ to $5{ }^{\circ} \mathrm{C}, 1 \mathrm{~h}$, then R.T. 4h, (ii) Appropriate amine, DMF, R.T., 1h, then $90{ }^{\circ} \mathrm{C}, 2 \mathrm{~h}$.

In the current work, these compounds were re-synthesized by reacting of intermediate compound 1 with aromatic and aliphatic amines. In the first step, intermediate compound $\mathbf{1}$ was $\mathrm{N}$ alkylated with different substituted aromatic amines to produce compounds $\mathbf{2}$ (a-e). After that, the final chloro atom of the second intermediate compounds 2 (a-e) was reacted with dimethylamine, morpholine 
or piperidine to obtain compounds 3 (a-o). Experimental details, physicochemical, and spectroscopic characterization of synthesized compounds 2 (a-e) and $\mathbf{3}$ (a-o) have been previously presented by us. ${ }^{28}$

\subsection{Determination of Antioxidant and Anticholinesterase Activity 2 (a-e) and $\mathbf{3}(\boldsymbol{a}-\boldsymbol{o})$.}

\subsubsection{DPPH Radical Scavenging Ability}

The DPPH (2,2-diphenyl-1-picrylhydrazyl) radical scavenging activity of the re-synthesized compounds were determined by spectrophotometric method. ${ }^{29,30}$ Different amounts of each compound were completed to $40 \mu \mathrm{L}$ with DMSO. $160 \mu \mathrm{L} 0.1 \mathrm{mM}$ DDPH solution was added to it. Absorption was measured at $517 \mathrm{~nm}$ after the mixture was left in the dark for 30 minutes. Free radical, DPPH, percent (I \%) inhibition calculated according to the formula:

$$
\mathrm{I} \%=\left(\mathrm{A}_{\text {control }}-\mathrm{A}_{\text {sample }}\right) / \mathrm{A}_{\text {control }} \times 100 \text {; }
$$

$\mathrm{A}_{\text {control }}$ is the absorbance of the control reaction (it contains all reagents except the compounds tested), and $\mathrm{A}_{\text {sample }}$ is the absorbance of the test compounds. The tests were done three times. Butylated hydroxyanisol (BHA), butylated hydroxytoluene (BHT) and $\alpha$-tocopherol $(\alpha$-Toc) were used as positive control.

\subsubsection{ABTS Cation Radical Decolorization}

The percent inhibition of decolonization of the ABTS (2,2'-azino-bis (3-ethylbenzotiazolin6-sulfonic acid)) cation radical is achieved as a function of concentration and time. As standard; BHT, BHA and $\alpha$-Toc compounds are used. ${ }^{31,32}$ Compounds synthesized in different concentrations and a 160 $\mu \mathrm{L} 7 \mathrm{mM}$ ABTS solution are added to each well. Compounds held 6 minutes at room temperature. Then, absorbance values are measured at $734 \mathrm{~nm}$. ABTS cation radical decolonization activities were determined using the following equation:

$$
\% \text { Inhibition }=\left(\mathrm{A}_{\text {control }}-\mathrm{A}_{\text {sample }}\right) / \mathrm{A}_{\text {control }} \times 100
$$

The tests were done three times. BHA, BHT and $\alpha$-Toc compounds have been used as positive control.

\subsubsection{Metal Chelate}

Chelating ability of synthesized compounds were determined by the method of Dinis et al. ${ }^{33}$ Different concentrations of the compounds tested were added to each well. Then, each sample was mixed with $4 \mu \mathrm{L} 2 \mathrm{mM}$ of iron (II) chloride. The reaction was initiated by adding $8 \mu \mathrm{L} 5 \mathrm{mM}$ ferrozine. The resulting mixture is kept at room temperature for 10 minutes. Subsequently, absorbance values were measured at $562 \mathrm{~nm}$. The results were expressed as a percentage of inhibition of ferrozin- $\mathrm{Fe}^{2+}$ complex formation. EDTA has been used as a positive control. Percent inhibition of ferrozin- $\mathrm{Fe}^{2+}$ complex formation was calculated using the formula given below:

$$
\text { Chelation ability }(\%)=\left(\mathrm{A}_{\text {control }}-\mathrm{A}_{\text {sample }}\right) / \mathrm{A}_{\text {control }} \times 100
$$

Tests were repeated 3 times.

\subsubsection{Cupric Reducing Antioxidant Capacity (CUPRAC)}

The method involves the reduction of $\mathrm{Cu}(\mathrm{II})$-Neocuproin to the colored form $\mathrm{Cu}(\mathrm{I})-\mathrm{Neocuproin}$ chelate in the presence of antioxidant compounds. ${ }^{34}$ The compounds synthesized were added to each well in different concentrations. $61 \mu \mathrm{L}$ solutions of $\mathrm{CuCl}_{2}$, Neocuproine and $\mathrm{NH}_{4} \mathrm{OAc}$ were added to it. After waiting at room temperature for 1 hour, absorption values were measured at $450 \mathrm{~nm}$. The measured 
absorbance values were compared with the BHA, BHT and $\alpha$-TOC molecules used as standard. Tests were repeated 3 times.

\subsubsection{Anticholinesterase Activity}

The inhibitory effect of synthesized compounds on BChE and AChE activities was applied according to the spectrophotometric method of Ellman et al. ${ }^{35}$ Compounds to be tested were dissolved in DMSO in order to prepare stock solutions at a concentration of $4 \mathrm{mM}$. Aliquots of $150 \mu \mathrm{L} 100 \mathrm{mM}$ sodium phosphate buffer ( $\mathrm{pH} 8.0$ ), sample solution and AChE (or BChE) solution were mixed. After incubating at $15{ }^{\circ} \mathrm{C}$ for 25 minutes, DTNB (5,5'-dithio-bis (2-nitro-benzoic acid)) was added. $10 \mu \mathrm{L}$ acetylthiocoline iodide (or butyrylthiocoline iodide) was added to the reaction. 30 minutes after the addition of substrates (acetylthiocoline iodide or butyrylthiocoline iodide) and absorption values were measured at $412 \mathrm{~nm}$.

$$
\% \text { Inhibition }=\left(\mathrm{A}_{\text {control }}-\mathrm{A}_{\text {sample }}\right) / \mathrm{A}_{\text {control }} \times 100
$$

Tests were repeated 3 times. Galantamine was preferred as a positive control. $\mathrm{IC}_{50}$ value was determined by a concentration-inhibition graph.

\subsection{Statistical Analysis}

The results of the antioxidant and anticholinesterase activity assays are expressed as the mean \pm SD of three parallel measurements. The statistical significance was estimated using a Student's t-test, where $\mathrm{p}$-values $<0.05$ were considered significant.

\section{Results and Discussion}

In the present study, a large series of 1,3,5-triazine-substituted ureido benzenesulfonamides were re-synthesized as a general synthetic route shown in Scheme 1. The current study focused on the in vitro antioxidant activity of the target compounds 2 (a-e) and 3 (a-o) by using several assays, including DPPH free radical scavenging, ABTS cation radical scavenging, cupric reducing (CUPRAC) and metal chelating methods. The acetylcholinesterase (AChE) and butyrylcholinesterase (BChE) activities of these compounds were also investigated.

The DPPH activity of the re-synthesized compounds was tested and compared with standards BHT, BHA and $\alpha$-TOC (Table 1). In general, compounds showed moderate DPPH activity with $\mathrm{IC}_{50}$ values ranging from 91.46 to $730.61 \mu \mathrm{M}$. The most active compound was $3 \mathbf{i}\left(\mathrm{R}_{1}=4-\mathrm{Cl}\right.$ and $\mathrm{R}_{2}=$ piperidine) with $\mathrm{IC}_{50}$ values of $91.46 \mu \mathrm{M}$. On the other hand, best biological activities among the tests that they were conducted in the current work were obtained against ABTS cation radical scavenging assays. All compounds from the current series showed better ABTS cation radical scavenging activity than standards BHT ( $\left.\mathrm{IC}_{50}: 26.54 \mu \mathrm{M}\right)$, BHA $\left(\mathrm{IC}_{50}: 45.40 \mu \mathrm{M}\right)$ and $\alpha$-TOC $\left(\mathrm{IC}_{50}: 34.12 \mu \mathrm{M}\right)$ with $\mathrm{IC}_{50}$ values of 8.60 to $20.59 \mu \mathrm{M}$ (Table 1). Compounds $\mathbf{3 e}, \mathbf{3 i}, \mathbf{3 k}, \mathbf{3 1}, \mathbf{3 n}$, and $\mathbf{3 o}$ showed $<10 \mu \mathrm{M}$ activity. Interestingly, these compounds (3e, 3i $, \mathbf{3 k}, \mathbf{3 l}, \mathbf{3 n}$, and 3o) substituted on one site with morpholine or piperidine. More specifically, compounds $\mathbf{3 e}, \mathbf{3 k}$ and $\mathbf{3 n}$ substituted one one side with morpholine and on the other side with 4-F, 3,4-diCl and 4- $\mathrm{SO}_{2} \mathrm{NH}_{2}$, and shows very close activity to each other with $\mathrm{IC}_{50}$ values of 8.60, 9.83, and $8.65 \mu \mathrm{M}$, respectively. Similarly, compounds 3i, 3i, and $\mathbf{3 o}$ substituted on one side with piperidine and on the other side with 4-Cl, 3,4-diCl and 4- $\mathrm{SO}_{2} \mathrm{NH}_{2}$, exhibits great antioxidant activity with $\mathrm{IC}_{50}$ values of $9.42,8.72$, and $9.08 \mu \mathrm{M}$, respectively. The metal chelating effect of $1,3,5-$ triazine-substituted ureido benzenesulfonamides on iron (II) ions was also summarized in Table 1 and compared with standard EDTA. Only compound $\mathbf{3 a}\left(\mathrm{R}_{1}=-\mathrm{H}\right.$ and $\left.\mathrm{R}_{2}=-\mathrm{N}(\mathrm{Me})_{2}\right)$ showed better activity than standard EDTA ( IC $_{50}: 52.35 \mu \mathrm{M}$ ) with an $\mathrm{IC}_{50}$ value of $36.33 \mu \mathrm{M}$. The compound $\mathbf{3 k}\left(\mathrm{IC}_{50}: 54.88\right.$ $\mu \mathrm{M})$ was also indicated to close activity to standard EDTA. Compounds $\mathbf{2 e}, \mathbf{3 i}, \mathbf{3 j}, \mathbf{3 l}$ and $\mathbf{3 n}$ showed moderate activity with $\mathrm{IC}_{50}$ values spanning between 81.34 to $95.94 \mu \mathrm{M}$. 
Table 1. DPPH radical scavenging, ABTS cation radical decolorization and metal chelating activities of 1,3,5-triazine-substituted ureido benzenesulfonamides $\mathbf{2}$ (a-e) and 3 (a-o) and controls BHA, BHT, $\alpha$-Toc, and EDTA

\begin{tabular}{|c|c|c|c|c|c|}
\hline \multirow[b]{2}{*}{ Comp. } & \multirow[b]{2}{*}{$\mathbf{R}_{1}$} & \multirow[b]{2}{*}{$\mathbf{R}_{2}$} & \multicolumn{3}{|c|}{$\mathrm{IC}_{50}(\mu \mathrm{M})^{\mathrm{a}}$} \\
\hline & & & $\begin{array}{l}\text { DPPH Free Radical } \\
\text { Scavenging Activity }\end{array}$ & $\begin{array}{l}\text { ABTS Cation Radical } \\
\text { Scavenging Activity }\end{array}$ & $\begin{array}{c}\text { Metal Chelating } \\
\text { Activity }\end{array}$ \\
\hline $2 \mathbf{a}$ & $-\mathrm{H}$ & $-\mathrm{Cl}$ & $359.28 \pm 1.00$ & $12.00 \pm 0.56$ & $>1000$ \\
\hline $2 \mathrm{~b}$ & $4-F$ & $-\mathrm{Cl}$ & $311.14 \pm 0.40$ & $20.07 \pm 0.03$ & $>1000$ \\
\hline $2 c$ & $4-\mathrm{Cl}$ & $-\mathrm{Cl}$ & $730.61 \pm 0.85$ & $18.96 \pm 0.66$ & $195.36 \pm 0.15$ \\
\hline 2d & 3,4-diCl & $-\mathrm{Cl}$ & $459.77 \pm 0.63$ & $13.38 \pm 0.06$ & $164.74 \pm 0.05$ \\
\hline $2 e$ & $4-\mathrm{SO}_{2} \mathrm{NH}_{2}$ & $-\mathrm{Cl}$ & $665.24 \pm 0.71$ & $14.08 \pm 0.30$ & $81.34 \pm 0.22$ \\
\hline $3 \mathbf{a}$ & $-\mathrm{H}$ & $-\mathrm{N}(\mathrm{Me})_{2}$ & $371.64 \pm 0.50$ & $13.50 \pm 0.15$ & $36.33 \pm 0.49$ \\
\hline $3 \mathbf{b}$ & $-\mathrm{H}$ & Morpholine & $152.77 \pm 0.33$ & $11.26 \pm 0.07$ & $162.49 \pm 0.68$ \\
\hline $3 c$ & $-\mathrm{H}$ & Piperidine & $163.91 \pm 0.45$ & $11.21 \pm 0.60$ & $>1000$ \\
\hline 3d & $4-F$ & $-\mathrm{N}(\mathrm{Me})_{2}$ & $107.54 \pm 0.93$ & $10.30 \pm 0.21$ & $>1000$ \\
\hline $3 e$ & $4-\mathrm{F}$ & Morpholine & $165.47 \pm 0.41$ & $8.60 \pm 0.13$ & $>1000$ \\
\hline $3 f$ & $4-\mathrm{F}$ & Piperidine & $395.72 \pm 0.55$ & $13.07 \pm 0.85$ & $>1000$ \\
\hline $3 g$ & $4-\mathrm{Cl}$ & $-\mathrm{N}(\mathrm{Me})_{2}$ & $200.29 \pm 0.32$ & $10.51 \pm 0.10$ & $>1000$ \\
\hline $3 h$ & $4-\mathrm{Cl}$ & Morpholine & $204.33 \pm 0.70$ & $10.38 \pm 0.89$ & $>1000$ \\
\hline $3 \mathbf{i}$ & $4-\mathrm{Cl}$ & Piperidine & $91.46 \pm 0.06$ & $9.42 \pm 0.38$ & $85.33 \pm 0.24$ \\
\hline $3 \mathbf{j}$ & 3,4-diCl & $-\mathrm{N}(\mathrm{Me})_{2}$ & $322.89 \pm 0.65$ & $20.59 \pm 0.51$ & $95.72 \pm 0.07$ \\
\hline $3 \mathbf{k}$ & 3,4-diCl & Morpholine & $193.38 \pm 0,39$ & $9.53 \pm 0.28$ & $54.88 \pm 0.43$ \\
\hline 31 & 3,4-diCl & Piperidine & $306.49 \pm 0,45$ & $8.72 \pm 0.14$ & $95.55 \pm 0.81$ \\
\hline $3 m$ & $4-\mathrm{SO}_{2} \mathrm{NH}_{2}$ & $-\mathrm{N}(\mathrm{Me})_{2}$ & $297.48 \pm 0.16$ & $13.16 \pm 0.86$ & $125.64 \pm 0.14$ \\
\hline $3 n$ & $4-\mathrm{SO}_{2} \mathrm{NH}_{2}$ & Morpholine & $185.81 \pm 0.26$ & $8.65 \pm 0.01$ & $95.94 \pm 0.91$ \\
\hline 30 & $4-\mathrm{SO}_{2} \mathrm{NH}_{2}$ & Piperidine & $134.04 \pm 0.31$ & $9.08 \pm 0.57$ & $230.43 \pm 0.93$ \\
\hline BHA $^{\mathbf{b}}$ & ------ & ------ & $61.72 \pm 0.85$ & $45.40 \pm 1.08$ & ------ \\
\hline $\mathbf{B H T}^{\mathbf{b}}$ & ------ & ------ & $232.11 \pm 3.01$ & $26.54 \pm 0.18$ & ------ \\
\hline$\stackrel{\alpha-}{\text { TOC }^{b}}$ & ------ & ------ & $56.86 \pm 0.77$ & $34.12 \pm 041$ & ------ \\
\hline EDTA $^{\mathbf{b}}$ & ------ & ------ & ------ & ------ & $52.35 \pm 1.15$ \\
\hline
\end{tabular}

${ }^{\mathrm{a}} \mathrm{IC}_{50}$ values represent the means (standard deviation of three parallel measurements $(\mathrm{p}<0.05)$.

${ }^{\mathrm{b}}$ Reference compounds.

The cupric reducing antioxidant capacity (CUPRAC) analyses was also applied to determine the antioxidant capacity of the re-synthesized 1,3,5-triazine-substituted ureido benzenesulfonamides 2 (a-e) and $\mathbf{3}$ (a-o) and the obtained results were compared with the standards BHT, BHA and $\alpha$-TOC as depicted in Table 2. As expected, the antioxidant activity of the compounds increased with increasing concentration (10 to $100 \mu \mathrm{M})$. In the current study, the compounds $2 \mathbf{a}\left(\mathrm{R}_{1}=-\mathrm{H}\right.$ and $\left.\mathrm{R}_{2}=-\mathrm{Cl}\right), \mathbf{3 d}\left(\mathrm{R}_{1}=4-\right.$ $\mathrm{F}$ and $\left.\mathrm{R}_{2}=-\mathrm{N}(\mathrm{Me})_{2}\right)$, and $\mathbf{3 e}\left(\mathrm{R}_{1}=4-\mathrm{F}\right.$ and $\mathrm{R}_{2}=$ morpholine $)$ showed better activity than the all standards at $10 \mu \mathrm{M}$. The activity of all compounds were less than the standards BHT and BHA at $100 \mu \mathrm{M}$, but several of them (such as $\mathbf{2 a}, \mathbf{2 d}, \mathbf{3 d}, \mathbf{3 e}$, and $\mathbf{3 h}$ ) were more potent than the standard $\alpha$-TOC. 
Table 2. Absorbance values for the cupric ion reducing antioxidant capacity (CUPRAC), of 1,3,5triazine-substituted ureido benzenesulfonamides 2 (a-e) and 3 (a-o) and controls BHA, BHT, and $\alpha$ Toc.

\begin{tabular}{|c|c|c|c|c|c|c|}
\hline \multirow[b]{2}{*}{ Comp. } & \multirow[b]{2}{*}{$\mathbf{R}_{1}$} & \multirow[b]{2}{*}{$\mathbf{R}_{2}$} & \multicolumn{4}{|c|}{ Absorbance Values $^{\text {a }}$} \\
\hline & & & $10 \mu \mathrm{M}$ & $25 \mu \mathrm{M}$ & $50 \mu \mathrm{M}$ & $100 \mu \mathrm{M}$ \\
\hline $2 a$ & $-\mathrm{H}$ & $-\mathrm{Cl}$ & $0.315 \pm 0.098$ & $0.496 \pm 0.109$ & $0.877 \pm 0.071$ & $1.453 \pm 0.008$ \\
\hline $2 b$ & $4-\mathrm{F}$ & $-\mathrm{Cl}$ & $0.254 \pm 0.036$ & $0.421 \pm 0.034$ & $0.584 \pm 0.044$ & $0.700 \pm 0.025$ \\
\hline $2 c$ & $4-\mathrm{Cl}$ & $-\mathrm{Cl}$ & $0.207 \pm 0.019$ & $0.295 \pm 0.023$ & $0.431 \pm 0.049$ & $0.612 \pm 0.047$ \\
\hline 2d & 3,4-diCl & $-\mathrm{Cl}$ & $0.227 \pm 0.037$ & $0.389 \pm 0.034$ & $0.597 \pm 0.027$ & $0.941 \pm 0.030$ \\
\hline $2 e$ & $4-\mathrm{SO}_{2} \mathrm{NH}_{2}$ & $-\mathrm{Cl}$ & $0.171 \pm 0.026$ & $0.257 \pm 0.005$ & $0.391 \pm 0.004$ & $0.527 \pm 0.032$ \\
\hline $3 \mathbf{a}$ & $-\mathrm{H}$ & $-\mathrm{N}(\mathrm{Me})_{2}$ & $0.235 \pm 0.017$ & $0.404 \pm 0.031$ & $0.533 \pm 0.058$ & $0.650 \pm 0.044$ \\
\hline $3 \mathbf{b}$ & $-\mathrm{H}$ & Morpholine & $0.232 \pm 0.025$ & $0.387 \pm 0.016$ & $0.636 \pm 0.024$ & $0.935 \pm 0.011$ \\
\hline $3 c$ & $-\mathrm{H}$ & Piperidine & $0.275 \pm 0.039$ & $0.456 \pm 0.019$ & $0.656 \pm 0.029$ & $0.826 \pm 0.023$ \\
\hline 3d & $4-\mathrm{F}$ & $-\mathrm{N}(\mathrm{Me})_{2}$ & $0.298 \pm 0.045$ & $0.435 \pm 0.028$ & $0.780 \pm 0.035$ & $0.918 \pm 0.007$ \\
\hline $3 e$ & $4-\mathrm{F}$ & Morpholine & $0.393 \pm 0.061$ & $0.503 \pm 0.047$ & $0.753 \pm 0.035$ & $0.989 \pm 0.059$ \\
\hline $3 f$ & $4-\mathrm{F}$ & Piperidine & $0.241 \pm 0.044$ & $0.337 \pm 0.015$ & $0.457 \pm 0.014$ & $0.832 \pm 0.008$ \\
\hline $3 g$ & $4-\mathrm{Cl}$ & $-\mathrm{N}(\mathrm{Me})_{2}$ & $0.232 \pm 0.009$ & $0.348 \pm 0.031$ & $0.467 \pm 0.009$ & $0.672 \pm 0.015$ \\
\hline $3 h$ & $4-\mathrm{Cl}$ & Morpholine & $0.246 \pm 0.036$ & $0.375 \pm 0.026$ & $0.615 \pm 0.015$ & $0.992 \pm 0.032$ \\
\hline $3 \mathbf{i}$ & $4-\mathrm{Cl}$ & Piperidine & $0.209 \pm 0.012$ & $0.346 \pm 0.022$ & $0.503 \pm 0.042$ & $0.856 \pm 0.080$ \\
\hline $3 \mathbf{j}$ & 3,4-diCl & $-\mathrm{N}(\mathrm{Me})_{2}$ & $0.177 \pm 0.039$ & $0.194 \pm 0.005$ & $0.271 \pm 0.024$ & $0.274 \pm 0.023$ \\
\hline $3 \mathbf{k}$ & 3,4-diCl & Morpholine & $0.217 \pm 0.006$ & $0.321 \pm 0.005$ & $0.490 \pm 0.016$ & $0.643 \pm 0.039$ \\
\hline 31 & 3,4-diCl & Piperidine & $0.175 \pm 0.061$ & $0.311 \pm 0.015$ & $0.442 \pm 0.003$ & $0.639 \pm 0.028$ \\
\hline $3 m$ & $4-\mathrm{SO}_{2} \mathrm{NH}_{2}$ & $-\mathrm{N}(\mathrm{Me})_{2}$ & $0.144 \pm 0.008$ & $0.201 \pm 0.005$ & $0.279 \pm 0.012$ & $0.427 \pm 0.012$ \\
\hline $3 n$ & $4-\mathrm{SO}_{2} \mathrm{NH}_{2}$ & Morpholine & $0.188 \pm 0.007$ & $0.306 \pm 0.017$ & $0.441 \pm 0.003$ & $0.541 \pm 0.042$ \\
\hline 30 & $4-\mathrm{SO}_{2} \mathrm{NH}_{2}$ & Piperidine & $0.212 \pm 0.006$ & $0.323 \pm 0.017$ & $0.516 \pm 0.039$ & $0.686 \pm 0.037$ \\
\hline $\mathbf{B H A}^{\mathbf{b}}$ & ------ & ------ & $0.288 \pm 0.015$ & $0.572 \pm 0.046$ & $1.026 \pm 0.013$ & $1.984 \pm 0.035$ \\
\hline $\mathbf{B H T}^{\mathbf{b}}$ & ------ & ------ & $0.303 \pm 0.010$ & $0.610 \pm 0.010$ & $1.167 \pm 0.024$ & $2.000 \pm 0.173$ \\
\hline $\begin{array}{c}\alpha- \\
\text { TOC }^{\mathbf{b}}\end{array}$ & ------ & ------ & $0.296 \pm 0.012$ & $0.296 \pm 0.012$ & $0.482 \pm 0.017$ & $0.912 \pm 0.065$ \\
\hline
\end{tabular}

${ }^{\mathrm{a}}$ Values expressed are means $\pm \mathrm{SD}$ of three parallel absorbance measurements $(\mathrm{p}<0.05)$

${ }^{\mathrm{b}}$ Reference compounds

In this study, a large series of re-synthesized 1,3,5-triazine-substituted ureido benzenesulfonamides $\mathbf{2}$ (a-e) and $\mathbf{3}$ (a-o) were also assessed to anticholinesterase (AChE and BChE) activity (Table 3 ). None of the compounds from the series showed any activity against AChE, except the compounds 3n (\% inhibition of 52.61)and 3o (\% inhibition of 4.38), which both have $-\mathrm{SO}_{2} \mathrm{NH}_{2}$ substitution on their structures. On the other hand, potent inhibition was observed against BChE with some of the compounds. More specifically, compound $3 \mathbf{m}\left(\mathrm{R}_{1}=4-\mathrm{SO}_{2} \mathrm{NH}_{2}\right.$ and $\left.\mathrm{R}_{2}=-\mathrm{N}(\mathrm{Me})_{2}\right)$ showed great BChE inhibition with \% inhibition of 93.77 at $200 \mu \mathrm{M}$ concentration which is better than the standard drug galantamine (\% inhibition 87.86). Also, the compounds $\mathbf{3 c}, \mathbf{3 g}, \mathbf{3 i}$ and $\mathbf{3 l}$ exhibited good inhibition with \% inhibition values are ranging between 74.89 to 80.85 at $200 \mu \mathrm{M}$ concentration, which 
these compounds interestingly have piperidine substitution on one site, except the compound $\mathbf{3 g}\left(\mathrm{R}_{1}=\right.$ 4-Cl and $\mathrm{R}_{2}=-\mathrm{N}(\mathrm{Me})_{2}$ ). Some of the compounds from the series (such as $\mathbf{2 a}, \mathbf{2 b}, \mathbf{2 e}, \mathbf{3 b}, \mathbf{3 e}, \mathbf{3 h}, \mathbf{3} \mathbf{j}$ and 3k) displayed non activity against BChE. Interestingly, most of these non active compounds have morpholine or $-\mathrm{Cl}$ substitution on their one side.

Table 3. Anticholinesterase activity of 1,3,5-triazine-substituted ureido benzenesulfonamides $\mathbf{2}$ (a-e) and $\mathbf{3}$ (a-o) at $200 \mu \mathrm{M}$ and standard drug galantamine.

\begin{tabular}{|c|c|c|c|c|}
\hline Comp. & $\mathbf{R}_{1}$ & $\mathbf{R}_{2}$ & AChE (Inhibition \%) ${ }^{\mathrm{a}}$ & BChE (Inhibition \%) ${ }^{a}$ \\
\hline $2 \mathbf{a}$ & $-\mathrm{H}$ & $-\mathrm{Cl}$ & NA & NA \\
\hline $2 \mathbf{b}$ & $4-\mathrm{F}$ & $-\mathrm{Cl}$ & NA & NA \\
\hline 2c & $4-\mathrm{Cl}$ & $-\mathrm{Cl}$ & NA & $52.01 \pm 1.43$ \\
\hline \multirow[t]{2}{*}{ 2d } & 3,4-diCl & $-\mathrm{Cl}$ & NA & \\
\hline & & & & NA \\
\hline \multirow[t]{2}{*}{$2 e$} & $4-\mathrm{SO}_{2} \mathrm{NH}_{2}$ & $-\mathrm{Cl}$ & NA & \\
\hline & & & & $39.60 \pm 1.04$ \\
\hline 3a & $-\mathrm{H}$ & $-\mathrm{N}(\mathrm{Me})_{2}$ & NA & $37,63 \pm 0.73$ \\
\hline $3 \mathbf{b}$ & $-\mathrm{H}$ & Morpholine & NA & NA \\
\hline $3 c$ & $-\mathrm{H}$ & Piperidine & NA & $78.47 \pm 1.75$ \\
\hline 3d & $4-\mathrm{F}$ & $-\mathrm{N}(\mathrm{Me})_{2}$ & NA & $43.57 \pm 1.35$ \\
\hline $3 e$ & $4-\mathrm{F}$ & Morpholine & NA & NA \\
\hline 3f & $4-\mathrm{F}$ & Piperidine & NA & $61.22 \pm 1.86$ \\
\hline $3 g$ & $4-\mathrm{Cl}$ & $-\mathrm{N}(\mathrm{Me})_{2}$ & NA & $74.89 \pm 0.57$ \\
\hline $3 \mathbf{h}$ & $4-\mathrm{Cl}$ & Morpholine & NA & NA \\
\hline $3 \mathbf{i}$ & $4-\mathrm{Cl}$ & Piperidine & NA & $76.81 \pm 1.58$ \\
\hline 3j & 3,4-diCl & $-\mathrm{N}(\mathrm{Me})_{2}$ & NA & NA \\
\hline $3 \mathbf{k}$ & 3,4-diCl & Morpholine & NA & NA \\
\hline 31 & 3,4-diCl & Piperidine & NA & $80.85 \pm 0.61$ \\
\hline $3 m$ & $4-\mathrm{SO}_{2} \mathrm{NH}_{2}$ & $-\mathrm{N}(\mathrm{Me})_{2}$ & NA & $93.77 \pm 1.47$ \\
\hline $3 n$ & $4-\mathrm{SO}_{2} \mathrm{NH}_{2}$ & Morpholine & $52.61 \pm 1.03$ & $48.07 \pm 0.43$ \\
\hline 30 & $4-\mathrm{SO}_{2} \mathrm{NH}_{2}$ & Piperidine & $4.38 \pm 0.03$ & $62.74 \pm 1.70$ \\
\hline Galantamin $^{\mathrm{b}}$ & ----- & -- & $84.20 \pm 0.74$ & $87.86 \pm 0.24$ \\
\hline
\end{tabular}

\section{Conclusion}

In the current study, we report a series of twenty 1,3,5-triazine-substituted ureido benzenesulfonamides 2 (a-e) and $\mathbf{3}$ (a-o), which were successfully re-synthesized by condensation reaction of various aromatic/aliphatic amines on main intermediate compound 4-(3-(4,6-dichloro1,3,5-triazin-2-yl)ureido) benzenesulfonamide (1). These compounds were investigated as an antioxidant by using several assays such as DPPH, ABTS, metal chelating and CUPRAC methods. Anticholinesterase (AChE and $\mathrm{BChE}$ ) activities were also determined. In general, all compounds showed moderate to weak DPPH, metal chelating and CUPRAC activity. Importantly, all compounds were susceptible to ABTS assay, which all compounds were more active then the standards BHT, BHA and $\alpha$-TOC. On the other hand, all compounds were non active against AChE, except the compounds 3n and 3o, which they have some activity against AChE. Some of the compounds from the series showed moderate to good inhibition against BChE enzyme. More specifically, great inhibition was observed with the compound $\mathbf{3 m}$ which is more active than the standard drug galantamine against BChE enzyme. 


\section{Acknowledgments}

This work was partially funded by The Scientific and Technological Research Council of Turkey (TUBITAK) with Grant No: 315S103

\section{ORCID}

Nebih Lolak: 0000-0003-0578-2761

Muhammed Tuneg: 0000-0002-3001-0635

Aslinur Doğan: 0000-0002-2047-9229

Mehmet Boga: 0000-0003-4163-9962

Suleyman Akocak: 0000-0003-4506-5265

\section{References}

[1] Akocak, S.; Alam, M.R.; Shabana, A.M.; Sanku, R.K.K.; Vullo, D.; Thompson, H.; Swenson, E.R.; Supuran, C.T.; Ilies, M.A. PEGylated bis-sulfonamide carbonic anhydrase inhibitors can efficiently control the growth of several carbonic anhydrase IX-expressing carcinomas. J. Med. Chem. 2016, 59 (10), 5077-5088.

[2] Bano, S.; Javed, K.; Ahmad, S.; Rathish, I.G.; Singh, S.; Alam, M.S. Synthesis and biological evaluation of some new 2-pyrazolines bearing benzene sulfonamide moiety as potential anti-inflammatory and anticancer agents. Eur. J. Med. Chem. 2011, 46, 5763-5768.

[3] Lu, X.Y.; Wang, Z.C.; Ren, S.Z.; Shen, F.Q.; Man, R.J.; Zhu, H.L. Coumarin sulfonamides derivatives as potent and selective COX-2 inhibitors with efficacy in suppressing cancer proliferation and metastasis. Bioorg. Med. Chem. Lett. 2016, 26, 3491-3498.

[4] Akocak, S.; Lolak, N.; Bua, S.; Turel, I.; Supuran, C.T. Synthesis and biological evaluation of novel N, $\mathrm{N}^{\prime}$-diaryl cyanoguanidines acting as potent and selective carbonic anhydrase II inhibitors, Bioorg. Chem.. 2018, 77, 245-251.

[5] Akocak, S.; Boga, M.; Lolak, N.; Tuneg, M.; Sanku, R.K.K. Design, synthesis and biological evaluatuon of 1,3-diaryltriazene-substituted sulfonamides as antioxidant, acetylcholinesterase and butyrylcholinesterase inhibitors, J. Turk. Chem. Soc. Sec. A: Chem. 2019, 6(1), 63-70.

[6] Akocak, S.; Lolak, N.; Nocentini, A.; Karakoc, G.; Tufan, A.; Supuran, C.T. Synthesis and biological evaluation of novel aromatic and heterocyclic bis-sulfonamide Schiff bases as carbonic anhydrase I, II, VII and IX inhibitors. Bioorg. Med. Chem. 2017, 25, 3093-3097.

[7] Bag, S.; Tulsan, R.; Sood, A.; Cho, H.; Redjeb, H.; Zhou, W.; LeVine, H.; Torok, B.; Torok, M. Sulfonamides as multifunctional agents for Alzheimer's disease. Bioorganic Med Chem Lett. 2015, 25, 626-630.

[8] Makowska, A.; Saczewski, F.; Bednarski, P.J.; Saczewski, J.; Balewski, Ł. Hybrid molecules composed of 2,4-diamino-1,3,5-triazines and 2-imino-coumarins and coumarins. Synthesis and cytotoxic properties. Molecules 2018, 23(7), 1616.

[9] Cascioferro, S.; Parrino, B.; Spanò, V.; Carbone, A.; Montalbano, A.; Barraja, P.; Diana, P.; Cirrincione, G. 1,3,5-Triazines: A promising scaffold for anticancer drugs development. Eur. J. Med. Chem. 2017, 142, 523-549.

[10] Patel, R.; Keum, Y-S.; Park, S. Medicinal Chemistry Discoveries among 1,3,5-Triazines: Recent Advances (2000-2013) as Antimicrobial, Anti-TB, Anti-HIV and Antimalarials. Mini-Reviews Med. Chem. 2014, 14(9), 768-789.

[11] Singla, P.; Luxami, V.; Paul, K. Synthesis and in vitro evaluation of novel triazine analogues as anticancer agents and their interaction studies with bovine serum albumin. Eur. J. Med. Chem. 2016, 117, 59-69.

[12] Ceruso, M.; Vullo, D.; Scozzafava, A.; Supuran, C.T. Inhibition of human carbonic anhydrase isoforms IXIV with sulfonamides incorporating fluorine and 1,3,5-triazine moieties. Bioorg. Med. Chem. 2013, 21, 6929-6936.

[13] Havránková, E.; Csöllei, J.; Vullo, D.; Garaj, V.; Pazdera, P.; Supuran, C.T. Novel sulfonamide incorporating piperazine, aminoalcohol and 1,3,5-triazine structural motifs with carbonic anhydrase I, II and IX inhibitory action. Bioorg. Chem. 2018, 77, 25-37.

[14] Lolak, N.; Akocak, S.; Bua, S.; Supuran, C.T. Design, synthesis and biological evaluation of novel ureido benzenesulfonamides incorporating 1,3,5-triazine moieties as potent carbonic anhydrase IX inhibitors. Bioorg. Chem. 2019, 82, 117-122. 
[15] Lolak, N.; Akocak, S.; Türkeş, C.; Taslimi, P.; Isik, M.; Beydemir, S.; Gulcin, I.; Durgun, M. Synthesis, characterization, inhibition effects, and molecular docking studies as acetylcholinesterase, $\alpha$-glycosidase, and carbonic anhydrase inhibitors of novel benzenesulfonamides incorporating 1,3,5-triazine structural motifs. Bioorg. Chem. 2020, 100, 103897.

[16] Lolak, N.; Boga, M.; Tuneg, M.; Karakoc, G.; Akocak, S.; Supuran, C.T. Sulphonamides incorporating 1,3,5-triazine structural motifs show antioxidant, acetylcholinesterase, butyrylcholinesterase, and tyrosinase inhibitory profile. J. Enzyme Inhib. Med. Chem. 2020, 41(2), 413-418.

[17] Oguz, M.; Kalay, E.; Akocak, S.; Nocentini, A.; Lolak, N.; Boga, M.; Yilmaz, M.; Supuran, C.T. Synthesis of calix [4] azacrown substituted sulphonamides with acetylcholinesterase, butyrylcholinesterase, tyrosinase, and carbonic anhydrase inhibitory action. J. Enzyme Inhib. Med. Chem. 2020, 35(1), 12151223.

[18] Greig, N.H.; Lahiri, D.K.; Sambamurti, K. Butyrylcholinesterase: An important new target in Alzheimer's disease therapy. Int. Psychogeriatrics. 2002, 14, 77-91.

[19] Burmaoglu, S.; Yilmaz, A.O.; Polat, M.F.; Kaya, R.; Gulcin, İ.; Algul, O. Synthesis and biological evaluation of novel tris-chalcones as potent carbonic anhydrase, acetylcholinesterase, butyrylcholinesterase and $\alpha$-glycosidase inhibitors. Bioorg. Chem. 2019, 85, 191-197.

[20] Öztaşkin, N.; Çetinkaya, Y.; Taslimi, P.; Göksu, S.; Gülçin, I. Antioxidant and acetylcholinesterase inhibition properties of novel bromophenol derivatives. Bioorg. Chem. 2015, 60, 49-57.

[21] Ozgun, D.O.; Yamali, C.; Gul, H.I.; Taslimi, P.; Gulcin, I.; Yanik, T.; Supuran, C.T. Inhibitory effects of isatin Mannich bases on carbonic anhydrases, acetylcholinesterase, and butyrylcholinesterase. J. Enzyme Inhib. Med. Chem. 2016, 31(6), 1498-1501.

[22] Gülçin, İ.; Scozzafava, A.; Supuran, C.T.; Akincioglu, H.; Koksal, Z.; Turkan, F.; Alwasel, S. The effect of caffeic acid phenethyl ester (CAPE) on metabolic enzymes including acetylcholinesterase, butyrylcholinesterase, glutathione S-transferase, lactoperoxidase, and carbonic anhydrase isoenzymes I, II, IX, and XII. J. Enzyme Inhib. Med. Chem. 2016, 31(6), 1095-1101.

[23] Gulçin, İ.; Abbasova, M.; Taslimi, P.; Huyut, Z.; Safarova, L.; Sujayev, A.; Farzaliyev, V.; Beydemir, S.; Alwasel, S.H.; Supuran, C.T. Synthesis and biological evaluation of aminomethyl and alkoxymethyl derivatives as carbonic anhydrase, acetylcholinesterase and butyrylcholinesterase inhibitors. J Enzyme Inhib. Med. Chem. 2017, 32(1), 1174-1182.

[24] Casey, D.A.; Antimisiaris, D.; O’Brien, J. Drugs for Alzheimer's disease: Are they effective? P T. 2010, 35(4), 208-211.

[25] Wang, J.; Gu, B.J.; Masters, C.L.; Wang, Y.J. A systemic view of Alzheimer disease - Insights from amyloid- $\beta$ metabolism beyond the brain. Nat. Rev. Neurol. 2017, 13, 612-623.

[26] Işık, M.; Akocak, S.; Lolak, N.; Taslimi, P.; Turkes, C.; Gulcin, I.; Durgun, M.; Beydemir, S. Synthesis, characterization, biological evaluation, and in silico studies of novel 1,3-diaryltriazene-substituted sulfathiazole derivatives. Arch. Pharm. (Weinheim). 2020, DOI: 10.1002/ardp.202000102.

[27] Cai, P.; Fang, S.Q.; Yang, H.L.; Yang, X.L.; Liu, Q.H.; Kong, L.Y.; Wang, X.B. Donepezil-butylated hydroxytoluene (BHT) hybrids as Anti-Alzheimer's disease agents with cholinergic, antioxidant, and neuroprotective properties. Eur. J. Med. Chem. 2018, 157, 161-176.

[28] Lolak, N.; Akocak, S.; Bua, S.; Sanku, R.K.K.; Supuran, C.T. Discovery of new ureido benzenesulfonamides incorporating 1, 3, 5-triazine moieties as carbonic anhydrase I, II, IX and XII inhibitors. Bioorg. Med. Chem. 2019, 27, 1588-1594.

[29] Blois, M.S. Antioxidant determinations by the use of a stable free radical. Nature 1958, 181, 1199-1200.

[30] Akocak, S.; Lolak, N.; Tuneg, M.; Boga, M. Antioxidant, acetylcholinesterase and butyrylcholinesterase inhibition profiles of histamine Schiff bases. J. Turk. Chem. Soc. Sec. A: Chem. 2019, 6, 157-164.

[31] Re, R.; Pellegrini, N.; Proteggente, A.; Pannala, A.; Yang, M.; Rice-Evans, C. Antioxidant activity applying an improved ABTS radical cation decolorization assay. Free Radic. Biol. Med. 1999, 26(9-10), 1231-1237.

[32] Lolak, N.; Akocak, S. Biological evaluation of aromatic bis-sulfonamide Schiff bases as antioxidant, acetylcholinesterase and butyrylcholinesterase inhibitors. Cumhuriyet Sci. J. 2020, 41(2), 413-418.

[33] Dinis, T.C.; Madeira, V.M.; Almeida, L.M. Action of phenolic derivatives (acetaminophen, salicylate, and 5-aminosalicylate) as inhibitors of membrane lipid peroxidation and as peroxyl radical scavengers. Arch. Biochem. Biophys. 1994, 315(1), 161-165. 
[34] Apak, R.; Guclu, K.; Ozyurek, M.; Karademir, S.E. Novel total antioxidant capacity index for dietary polyphenols and vitamine $\mathrm{C}$ and $\mathrm{E}$, using their cupric ion reducing capability in the presence of neocuproine: CUPRAC Method, J. Agric. Food Chem. 2004, 52(26), 7970-7981.

[35] Ellman, G.L.; Courtney, K.D.; Andres, V.; Featherstone, R.M. A new and rapid colorimetric determination of acetylcholinesterase activity. Biochem. Pharmacol. 1961, 7, 88-95.

$$
\text { A } \underset{\substack{\text { publications } \\ \text { (0) } 2020 \text { ACG Publications }}}{\text { G }}
$$

